\title{
Tribological behavior of nanosecond-laser surface textured Ti6Al4V
}

\author{
Daniel Kümmel ${ }^{\mathrm{a}, \mathrm{b}}$, Marcus Hamann-Schroer ${ }^{\mathrm{a}, \mathrm{b}}$, Harald Hetzner ${ }^{\mathrm{c}}$, Johannes Schneider ${ }^{\mathrm{a}, \mathrm{b}, *}$ \\ ${ }^{\mathrm{a}}$ IAM Institute for Applied Materials, Karlsruhe Institute of Technology (KIT), Germany \\ ${ }^{\mathrm{b}}$ MicroTribology Center $\mu \mathrm{TC}$, Germany \\ ${ }^{\mathrm{c}}$ Liebherr-Aerospace Lindenberg GmbH, Germany
}

Keywords:

Titanium alloys

Ti6Al4V

Laser surface texturing

Surface engineering

\begin{abstract}
A B S T R A C T
Titanium alloys are used due to their high specific strength and remarkable corrosion resistance. Their wear resistance however is poor, which in this paper is counteracted by laser surface texturing. Linear textures were created by the use of a nanosecond-pulsed laser, accompanied by melt bulges of resolidified material on the sides. Packing density, finishing procedure and atmosphere during laser texturing were varied between the experiments. Melt bulges lasered in air turned out to be tribologically beneficial in grease-lubricated sliding contact, reducing wear volume on Ti6Al4V significantly by up to a factor of 160 , if a packing density of $5 \%$ or more was chosen. Further investigations of melt bulges with energy dispersive X-ray spectroscopy (EDX) and scanning transmission electron microscopy (STEM) revealed an increased content in interstitial oxygen and nitrogen and a purely martensitic $\alpha$ '-phase microstructure. Critical limitation of plastic deformation and a saturation of electronic bonds of the titanium atoms by interstitial elements is thought to be responsible for the reduction in adhesive tendency and therefore the pronounced decrease in wear.
\end{abstract}

\section{Introduction}

Titanium alloys like the $\alpha / \beta$-alloy Ti6Al4V exhibit tensile strengths of about $900 \mathrm{MPa}$, low density and excellent corrosion resistance which makes them favorable lightweight materials for example in aerospace industry. Their tribological properties however are poor. Wear behavior is governed by metallic adhesion and material transfer, which results in high wear rates, limiting the use of these alloys mostly to non-tribological applications [1,2].

Many surface engineering methods have been applied in order to improve the tribological performance of titanium alloys, such as thermochemical treatments, hard or soft coatings as well as mechanical treatments [3]. Also different surface texturing methods were used $[4,5]$, with laser surface texturing becoming increasingly established due to its flexibility and high precision [6]. Studies were also performed on laser textured Ti6Al4V surfaces in combination with the application of a diamond-like carbon coating [7] or solid lubricant [8]. Other researchers have investigated laser surface texturing of titanium alloys, regarding their biomedical use. They therefore focused mainly surface properties like wetting behavior and cell adhesion $[9,10]$.

When using nanosecond-pulsed lasers, surface textures are commonly accompanied by adjacent bulges of resolidified material, which will be referred to as "melt bulges" in the following. These result from a portion of the material only being molten by the laser and then being pushed to the sides of the texture by the portion of the material that has been vaporized, which is generally described as melt ejection. These melt bulges are commonly either polished off before the tribological experiments $[6,8,11,12]$ or the surfaces are prepared by shorter pico-/ femtosecond-pulses, which do not yield such melt bulges [13].

Compared to the large amount of research on laser surface texturing in general, only few researchers have studied the influence of laserinduced melt bulges on tribology. Some studies described a decrease in wear [14] or both friction and wear [15] compared to non-textured surfaces. Greiner et al. reported a decrease in friction under lubricated conditions and an increase under dry conditions, respectively [16]. Rapoport et al. also compared the results to a textured surface without bulges and found a better adhesion of solid lubricant for the surface with bulges [17].

However, all of the studies investigating the tribological effects of these melt bulges used tribologically advantageous materials such as grey cast iron [14], steels [16,17] or copper alloys [15] as sample materials. No such study on titanium alloys is known to the authors.

The aim of this paper is to investigate the potential for improving the tribological behavior of Ti6Al4V under grease-lubricated sliding by a linear laser surface texture with a focus on laser-induced melt bulges. With the intention to test this type of texture for the known enhancing

\footnotetext{
* Corresponding author

E-mail address: johannes.schneider@kit.edu (J. Schneider).
} 
Table 1

Laser parameters used for texturing the sample surface with channels of a width of $30 \mu \mathrm{m}$ and a depth of $10 \mu \mathrm{m}$.

\begin{tabular}{ll}
\hline Nominal laser power [W] & 9.1 \\
Pulse length [ns] & 26 \\
Pulse energy [mJ] & 0.091 \\
Average energy density [J/ $\left.\mathrm{cm}^{2}\right]$ & 8.8 \\
Pulse repetition rate $[\mathrm{kHz}]$ & 100 \\
Focusing length of lens [mm] & 100 \\
Process repetitions [-] & 2 \\
Pulse spacing [ $\mu \mathrm{m}]$ & 3.62 \\
Atmosphere & air / argon \\
\hline
\end{tabular}

mechanism of wear particle entrapment [4,18], the packing density (PD) of the textures was varied. Since the mechanical properties of titanium are known to be sensitive even to small amounts of interstitial elements like oxygen and nitrogen [19], the influence of atmosphere during laser texturing was also studied.

\section{Experimental}

\subsection{Materials}

Ti6Al4V material was used in annealed state according to AMS 4928 (ARA-T, Dinslaken, Germany), which results in a $\alpha / \beta$ ratio of $80 / 20$. The bulk material shows an equiaxed microstructure and a macroscopic hardness of $325 \mathrm{HV} 3$. Plates were prepared to $\varnothing 25 \mathrm{~mm} \times 8 \mathrm{~mm}$, ground on a metallographic grinding machine Buehler PowerPro 4000 with a 240 grit SiC paper under constant water supply in an omnidirectional fashion. Final plate roughness $R_{a}$ was around $0.25 \mu \mathrm{m}$.

The tribological system was chosen with respect to potential application of this technique in aerospace industry. Here, many tribological contacts involve components made from titanium alloys in contact with steel components. Contacts are often lubricated with aerospace greases since without lubrication, wear on the titanium parts would be even more severe.

For counter bodies, cylinder rollers (SKF, Schweinfurt, Germany) of $\emptyset 10 \mathrm{~mm} \times 10 \mathrm{~mm}$ made from 100Cr6 steel were used without further preparation. Roughness $\mathrm{R}_{\mathrm{a}}$ on the used cylinder surface was around $0.15 \mu \mathrm{m}$. The microstructure consists of annealed martensite, resulting in an average hardness of 750 HV3.

Before the experiments, both types of samples were cleaned in an ultrasonic bath using petroleum spirit and ethanol for 10 min each.

AeroShell Grease 33 (Shell, Hamburg, Germany) was used as lubricant, which has a base oil viscosity of $14.2 \mathrm{~mm}^{2} / \mathrm{s}$ and $3.4 \mathrm{~mm}^{2} / \mathrm{s}$ at $40{ }^{\circ} \mathrm{C}$ and $100{ }^{\circ} \mathrm{C}$, respectively. Worked penetration according to ASTM D217 is 297, which gives a NLGI consistency number of 1-2. This universal aerospace grease contains corrosion/oxidation inhibitors and load carrying additives in a lithium complex thickened synthetic base oil. Grease was applied excessively to the contact once, immediately before the experiment, to ensure lubrication throughout the entire experiment.

\subsection{Methods}

Laser surface texturing was performed using the laser system Piranha II (ACSYS, Kornwestheim, Germany) with a maximum power of $20 \mathrm{~W}$. As laser source, the Yb-doped glass fiber laser SPI G4 Z-Series EP (SPI, Southampton, United Kingdom) with a wavelength of $1060 \mathrm{~nm}$ was used, with the laser spot being moved across the surface by a Scanlab SCANcube 10 (Scanlab, Puchheim, Germany) galvanometer scanner. The laser was used in pulsed operation mode with every pulse creating a dimple. Continuous channels were formed due to overlapping pulses by $90 \%$. Laser parameters were kept constant as shown in Table 1. The energy density was assessed from the diameter of $36.2 \mu \mathrm{m}$ for one single laser dimple.

Linear channels with a semicircular cross section, width of $30 \mu \mathrm{m}$ and depth of $10 \mu \mathrm{m}$ were created by laser surface texturing (Fig. 3). As described in the introduction, channels were accompanied by melt bulges due to the use of a ns-laser source. Those had an average height of $13 \mu \mathrm{m}$ and an average width of $14 \mu \mathrm{m}$ on each side of the channel.

Packing density of the laser channels was varied between $0 \%$ and $200 \%$ as displayed in Table 2 , the packing density being defined as the channel width (measured without melt bulges) divided by the channel spacing.

Two samples were additionally prepared further by light grinding with fine 4000 grit SiC paper: One 10\% PD sample was ground until melt bulges were removed but laser channels still fully present and one sample of $200 \%$ PD was ground alike until the topmost material was removed and roughness was reduced to $\mathrm{R}_{\mathrm{a}} \approx 0.1 \mu \mathrm{m}$. The remaining subsurface material still consisted of remolten material, which was verified by focused ion beam (FIB) cross sections.

Tribological experiments were performed on an Optimol SRV tribometer (Optimol Instruments, Munich, Germany) in a reciprocating sliding motion perpendicular to the channel textures. Cylindrical counter bodies were arranged with their cylinder axis parallel to the surface and at an angle of $5^{\circ}$ to the sliding direction. Experimental parameters, were chosen with regard to a potential application in aerospace industry. Components there are often loaded by vibrations or elastic deflections and therefore small amplitudes. Normal load of $20 \mathrm{~N}$, frequency of $20 \mathrm{~Hz}$, stroke of $0.2 \mathrm{~mm}$ and a duration of $60 \mathrm{~min}$ as experimental parameters were constant throughout all the experiments. Ambient atmosphere was controlled to be $25 \pm 3{ }^{\circ} \mathrm{C}$ and $50 \pm 5 \% \mathrm{RH}$. The chosen temperature was the intrinsic temperature of the tribometer which was set up in a controlled laboratory environment. Humidity was controlled by a custom-built setup, where compressed, dry air was led through a pipe system filled with deionized water. All tribological experiments were conducted at least twice. If two experiments did not

Table 2

Tested laser channel packing densities and corresponding spacing with channels of a width of $30 \mu \mathrm{m}$ and a depth of $10 \mu \mathrm{m}$.

\begin{tabular}{|c|c|c|}
\hline Packing density $[\%]$ & Channel spacing $[\mu \mathrm{m}]$ & Comment \\
\hline 0 & - & non-textured reference \\
\hline 0.5 & 5000 & only two channels in contact with cylinder roller of tribological experiment \\
\hline 2.5 & 1200 & \\
\hline 5 & 600 & \\
\hline 10 & 300 & $\begin{array}{l}\text { for one set of experiments melt bulges were removed (marked as (br)); besides air, also Ar was used } \\
\text { as surrounding atmosphere during laser texturing (marked as (Ar)) }\end{array}$ \\
\hline 60 & 50 & channels and melt bulges directly neighboring each other, no reference surface left \\
\hline 200 & 15 & $\begin{array}{l}\text { resembling a laser-remelted surface with a } 50 \% \text { overlap of channels, no more channel-textures } \\
\text { observable, high roughness } R_{a} \approx 1.3 \mu \mathrm{m} \text {; for one set of experiments ground after texturing }\left(\mathrm{R}_{\mathrm{a}} \approx\right. \\
0.1 \mu \mathrm{m})\end{array}$ \\
\hline
\end{tabular}


agree, a third experiment was conducted.

For nano hardness measurements, metallographic cross sections of the laser channels were prepared. Polishing was done using diamond suspension of $6 \mu \mathrm{m}, 3 \mu \mathrm{m}$ and $1 \mu \mathrm{m}$. The final polishing step used a mixture of $90 \mathrm{ml}$ OP-U suspension and $10 \mathrm{ml}$ of $30 \% \mathrm{H}_{2} \mathrm{O}_{2}$ in order to prevent scratches on the surface that typically occur when polishing titanium alloys. A Fisherscope HV100 depth-sensing hardness tester (Fischer, Sindelfingen, Germany) with a Vickers indenter was used with a load of $5 \mathrm{mN}$. Since the cross section of melt bulges is small and difficult to hit with the indenter, an array of around 500 measuring points was placed over the cross section. By this, it was ensured that there were several hardness values of both melt bulges and bulk material in one measurement array.

Topography before and after the experiments was measured using a Sensofar Pl $\mu$ Neox confocal microscope (Sensofar, Barcelona, Spain). While for the plates in high wear regime, wear volume could directly be calculated from the confocal images of the wear scar, a different method had to be used for low wear samples. Here, the wear only affected the melt bulges and did not form a wear scar on the ground surface. First, the surfaces containing the worn melt bulges were imaged completely by confocal microscopy. Line profiles were drawn parallel to the channel on the melt bulges. From the profiles, the wear scar could be seen in circular silhouette of $\emptyset 10 \mathrm{~mm}$, corresponding to the counter body. Averaging multiple profiles, a wear depth could be read. From the confocal image of a single melt bulge, a CAD model was set up, which could be intersected with a model of the cylindrical counter body at the wear depth measured before. This yields a volume that needs to be multiplied by the number of melt bulges in contact. Accounting for the logarithmic shape of the cylinder roller, 1/8 of each side of the wear scar was weighted by a factor of 0.5 .

A FEI Helios Nanolab 650 Dual Beam Microscope (FEI, Hillsboro, Oregon, USA) was used for scanning electron microscopy (SEM) images. A thin, electron-transparent TEM foil was prepared from the melt bulges by focused ion beam (FIB) milling and microstructure was imaged by scanning transmission electron microscopy (STEM). Chemical composition of melt bulges was determined on the same TEM foil using energy dispersive X-ray spectroscopy (EDX) with a X-Max 80 detector (Oxford Instruments, Abingdon, UK).

\section{Results}

\subsection{Tribological properties}

Tribological experiments revealed two distinct kinds of behavior (Fig. 1).

The first kind showed a high and unsteady running-in friction with values for the average coefficient of friction up to 0.5 . After a sliding distance between 4 and $10 \mathrm{~m}$, an abrupt transition occurred to a lower

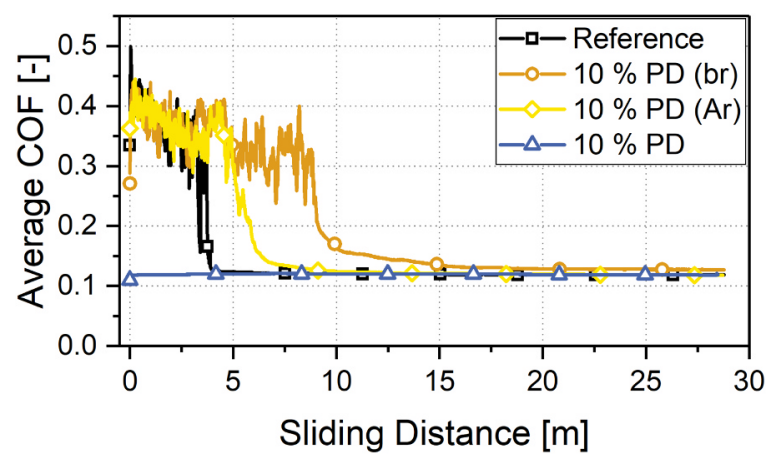

Fig. 1. Average coefficient of friction (COF) of an non-textured reference couple compared to laser textured sliding couples of $10 \%$ PD: as lasered in ambient air, with melt bulges removed (br) and lasered under argon atmosphere (Ar).

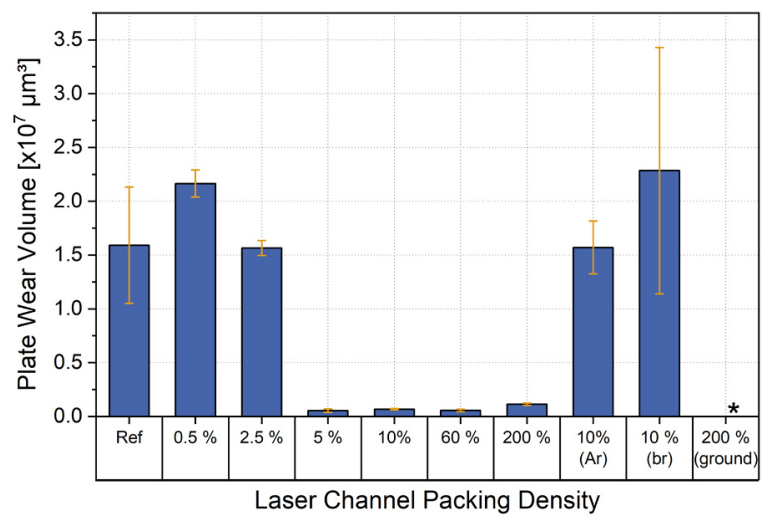

Fig. 2. Wear volume of Ti6Al4V plates with different packing densities of laser channels, on the right the experiments lasered under Ar-atmosphere (Ar) and with melt bulges removed (br). * for the experiments on the remelted and ground surface, the wear scar depth was below the surface roughness and therefore not measurable (estimated $\mathrm{V}_{\mathrm{w}}<0.01 \times 10^{7} \mu \mathrm{m}^{3}$ ). Error bars account for the variation between single experiments.

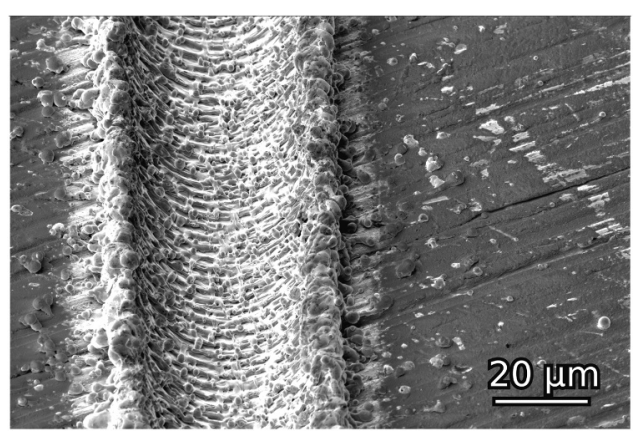

Fig. 3. SEM image of a laser channel (air, 10\% PD), as lasered, melt bulges visible on both sides of the channel.

coefficient of friction of 0.14 , which was constant for the rest of the experiment. The sliding distance at which the transition between friction states occurred significantly varied between identical experiments. This type of friction result was found for the non-textured reference, the sample with removed melt bulges (br) and the laser surface textured sample that was lasered under Ar-atmosphere (Ar) (both with $10 \%$ packing density). It is also valid for packing densities of $2.5 \%$ and below.

The second kind of friction behavior showed a constant coefficient of friction of 0.14 throughout the entire experiment. While the final coefficient of friction is very similar to the other experiments, the above-observed running-in behavior could not be found. This constant friction behavior is valid for samples that were laser surface textured in ambient air and tribologically tested with bulges for packing densities of $5 \%$ and above.

Fig. 2 shows the wear volume of the Ti6Al4V plates with different kinds of laser textures. Wear observed after the experiment correlated with the occurrence and also length of the running-in period, with longer running-in periods correlating with a higher wear volume. It again became evident that, as for friction, there is a separation into two distinct states of wear. The non-textured reference, Ar-lasered and samples with packing densities of $2.5 \%$ and below show a high wear volume between $1.6 \times 10^{7}$ and $2.3 \times 10^{7} \mu \mathrm{m}^{3}$. In contrast, samples lasered in air with packing densities of $5 \%$ and above show only little wear of $0.1 \times 10^{7} \mu \mathrm{m}^{3}$ and below, which is a significant reduction compared to samples in the high wear state. On the $200 \%$ (ground) samples, wear was not measurable by the methods applied here. Estimating the upper bound from surface roughness, wear was reduced by a factor of 160 compared to the reference samples. 


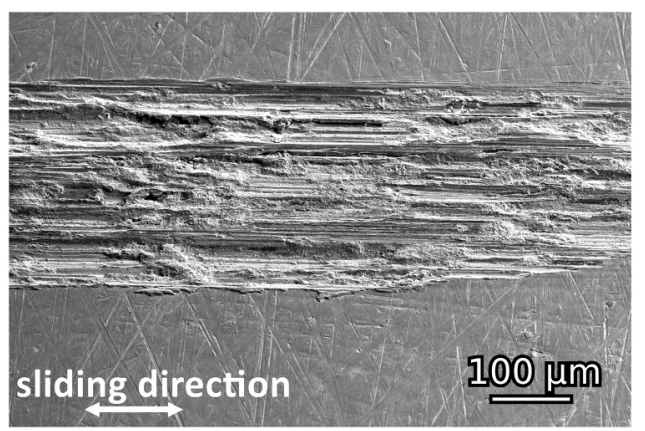

Fig. 4. SEM image of a wear scar on a non-textured Ti6Al4V plate with distinct signs of adhesive wear.

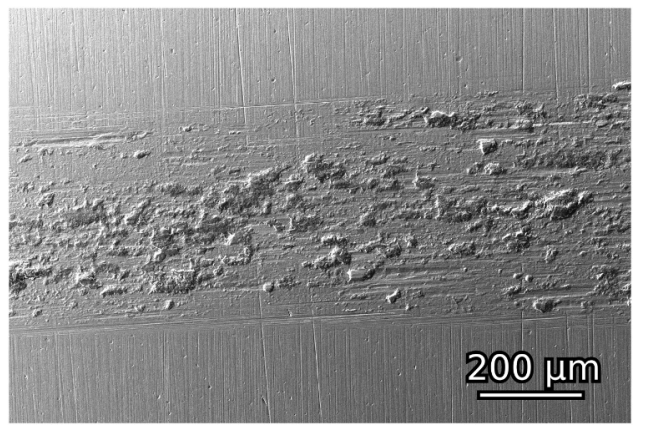

Fig. 5. SEM image of a wear scar on a $100 \mathrm{Cr} 6$ cylinder, run against an nontextured Ti6Al4V plate. Plate material was transferred onto the cylinder.

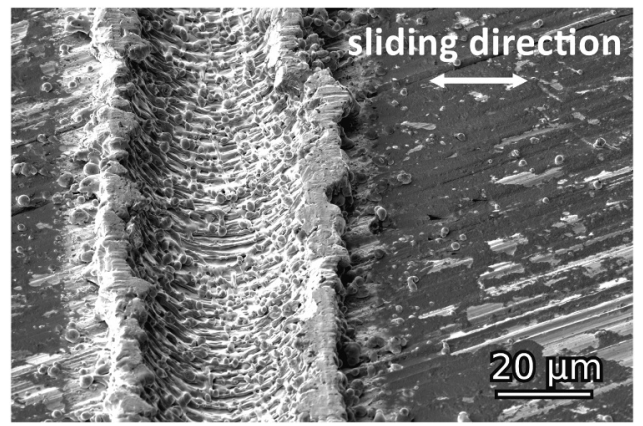

Fig. 6. SEM image of a laser channel (air, 10\% PD) after the tribological experiment; note that the ground surface on the sides of the channel has not been in contact with the counter body.

\subsection{Worn surfaces}

The amount of Ti6Al4V plate wear found after the experiments was influenced by the dominant wear mechanisms in the contact. The samples with a high running-in friction and high wear volume showed severe adhesive wear, with considerable material transfer from Ti6Al4V onto the $100 \mathrm{Cr} 6$ counter body (Fig. 4, Fig. 5), as it is often found in titanium tribosystems $[1,20]$.

On the other hand, for experiments with low and constant friction, wear was confined to the melt bulges surrounding the laser channels leading to significantly less wear volume. It should be noted that the counter body was supported solely by the melt bulges and did not come into contact with the ground surface (Fig. 6). Only mild abrasive grooves and no material transfer could be found on the counter body (Fig. 7). No signs of adhesive wear were observed on either of the surfaces.

Since the tribological behavior of the melt bulges was found to be significantly better, further analyses were conducted to identify

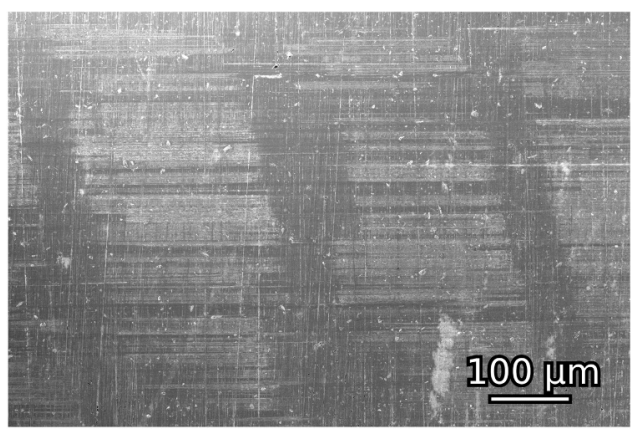

Fig. 7. SEM image of a worn cylinder (run against $10 \%$ PD, air), only slight abrasive marks can be seen where the cylinder was in contact with the melt bulges. Length of marks corresponds to the stroke of $200 \mu \mathrm{m}$.

mechanical, chemical and microstructural changes compared to bulk Ti6Al4V.

\subsection{Nano hardness}

Results of the nano hardness measurements are given in Table 3. The small load of $5 \mathrm{mN}$, with indentation depths below $0.16 \mu \mathrm{m}$ and indentation diagonal below $1.1 \mu \mathrm{m}$, enabled measuring hardness on the cross section of bulges (compare Fig. 8). Measurements revealed a twofold increase in hardness of the melt bulges lasered in air compared to bulk Ti6Al4V. Melt bulges lasered in Ar-atmosphere did not show a substantial difference in hardness compared to bulk material.

\subsection{Melt bulges around laser textures}

Fig. 8 shows a SEM image of a TEM foil prepared from a melt bulge adjacent to a laser channel as well as the oxygen and vanadium content determined by an EDX mapping of the TEM foil. Inside the melt bulge (1), a 10 at $\%$ higher oxygen content and 9 at $\%$ higher nitrogen content was measured, compared to the bulk material (2). The increased contents of oxygen and nitrogen inside the melt bulge seem credible as a result of high diffusivity in liquid phase during the laser process. Additionally, an oxygen-rich skin around the melt bulge can be observed. Vanadium content shows that there are vanadium-rich grains in bulk material, but not in the melt bulge. These correspond to $\beta$-grains, since vanadium acts as $\beta$-stabilizer in the $\alpha / \beta$ alloy Ti6Al4V [21]. The suppression of $\beta$-nucleation in the melt bulge led to an increase in vanadium content, as the vanadium from the $\beta$-phase is redistributed through the $\alpha$ '-matrix.

Microstructure inside the melt bulges was too fine to be observed by light microscopy and hardly visible even by scanning electron microscopy (SEM). Fig. 9 shows a scanning transmission electron microscopy (STEM) image of the microstructure. It depicts an acicular morphology consisting of needle-like $\alpha$ '-platelets with a maximum width of around $50 \mathrm{~nm}$. A couple of factors may have influenced the formation of this $\alpha$ 'martensite. Firstly, material is subjected to rapid cooling after redeposition of the molten Ti6Al4V during the laser surface texturing process, with high cooling rates favoring the precipitation of $\alpha$ '-phase. Ahmed and Rack state a critical cooling rate of $410 \mathrm{~K} / \mathrm{s}$ for a completely martensitic microstructure in Ti6Al4V [22]. While the real cooling rates are unknown, this seems plausible also for the resolidification of the laser-molten Ti6Al4V, since Sundaram et al. stated that the resolidification of laser-molten material only lasts timespans of nano- to microseconds [23]. Secondly, as shown in Fig. 8, the melt bulge has higher contents in oxygen and nitrogen, which act as $\alpha$-stabilizer in the Ti6Al4V alloy [21]. Oxygen is also known to induce or promote the martensitic transformation [24].

While the chemical differences between melt bulge and bulk material are quite pronounced, it should be noted that the concentration of 
Table 3

Maximum nano hardness measured in bulk and in melt bulges, average and standard deviation from seven measurements.

\begin{tabular}{llll} 
& Bulk Ti6Al4V & Melt bulges lasered in Ar-atmosphere & Melt bulges lasered in air \\
\hline max. Hardness [GPa] & $5.30 \pm 0.40$ & $4.94 \pm 0.35$ & $10.23 \pm 0.49$ \\
\hline
\end{tabular}

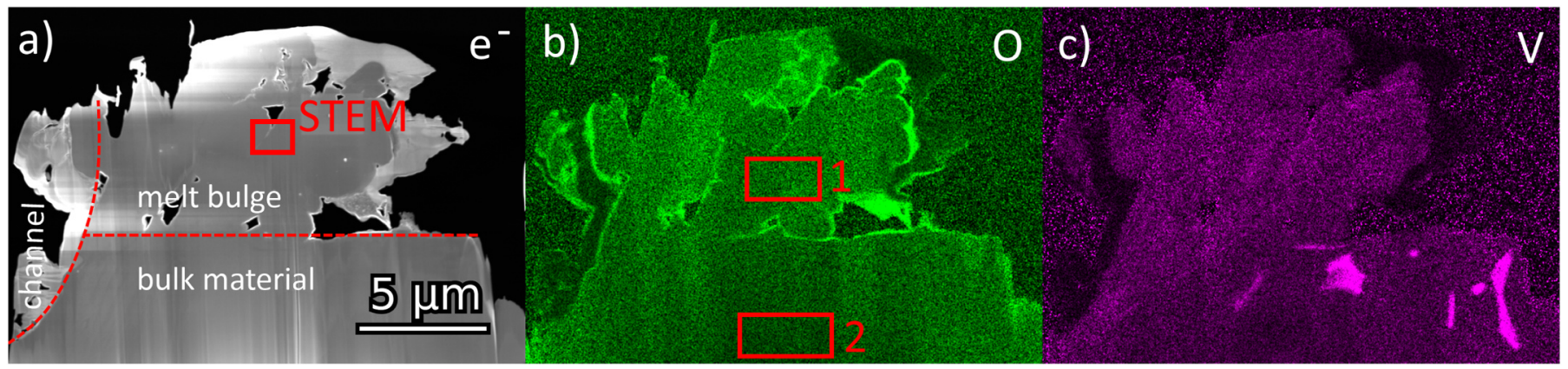

Fig. 8. SEM image (a) and EDX mappings of oxygen (b) and of vanadium (c) content in a melt bulge. The edge of the channel itself can be seen on the left of the images. Bright areas in a) show the platinum layer used to protect the sample from ion milling damage. Red box in a) indicates the position of STEM displayed in Fig. 9. Elemental concentration was taken from red boxes $(1,2)$ in b).

oxygen and nitrogen is still below their maximum solubility in titanium of 33 at $\%$ and 23 at\%, respectively $[25,26]$. Neither with STEM nor EDX, distinct oxides or nitrides could be found, indicating that these are either very small or not present at all. It is therefore concluded, that melt bulge material is in fact a solid solution of interstitial oxygen and nitrogen in the Ti6Al4V lattice.

\section{Discussion}

\subsection{Influence of lubricant additives}

A drastic decrease in wear was found in the reciprocating linecontact tribological experiments, for Ti6Al4V plates that were textured in air with a packing density of $5 \%$ or more.

In order to verify the potential influence of lubricant additives, further experiments on non-textured Ti6Al4V and 10\% PD laser surface textured Ti6Al4V were conducted in the same fashion as explained before. Instead of the fully formulated grease, a FVA 1 additive-free mineral reference oil with a viscosity $\left(14.9 \mathrm{~mm}^{2} / \mathrm{s}\right.$ and $3.5 \mathrm{~mm}^{2} / \mathrm{s}$ at $40{ }^{\circ} \mathrm{C}$ and $100{ }^{\circ} \mathrm{C}$, respectively) similar to the Aeroshell Grease 33 base oil was used as lubricant. These sliding couples showed the same two states of friction and the difference in total wear volume between textured and non-textured was comparable to the experiments lubricated with Grease 33. Particularly, the low wear state on laser surface textured Ti6Al4V was observed for experiments both lubricated by fully formulated grease and by additive-free base oil. It was therefore concluded that lubricant additives play no major role in the results shown.

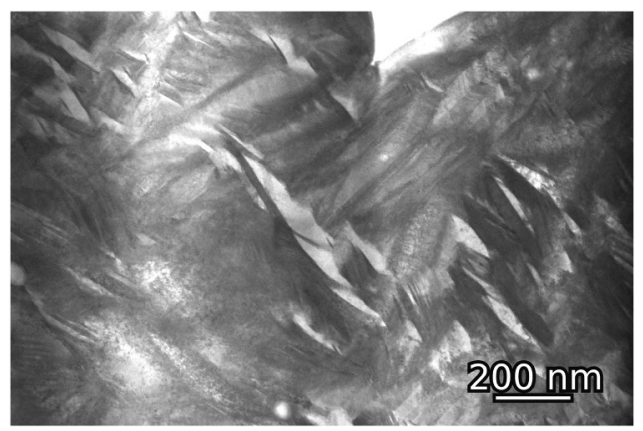

Fig. 9. STEM image of the microstructure inside a melt bulge around the channels.

\subsection{Influence of surface textures}

In literature on the tribology of textured surfaces in general, the mechanisms most often mentioned are additional micro hydrodynamic lift [27], entrapment of wear particles [4,18] and a secondary lubrication effect [28].

Other researchers investigating laser textured surfaces containing melt bulges attributed the improved behavior to the lubricant storage [14] or possible hydrodynamic lift [15]. Greiner et al. [16] ruled out possible material modification and credited the surface topography itself with the tribological differences.

Kovalchenko et al. on the other hand concluded that melt bulges need to be removed in order to optimize tribological properties [11]. In experiments shown here, removing the melt bulges (10\% (br)) led to severe adhesive wear, comparable to the non-textured reference. This indicates that the tribological enhancing mechanisms in this work are at least partially different from the above-mentioned mechanisms found in most of literature on laser surface texturing without melt bulges.

Firstly, the use of grease as lubricant decreases the influence of the micro hydrodynamic lift as a possible enhancing mechanism. It is further reduced due to the fact that the experiments were conducted in a reciprocating motion with small amplitudes and therefore small maximum sliding velocities below $13 \mathrm{~mm} / \mathrm{s}$.

Likewise, secondary lubrication due to surface textures is thought to play no major role since the experiments were not conducted under starved lubrication and contacts were greased excessively before the experiments.

Tian et al. also found a correlation of contact width and friction coefficient on linearly textured titanium surfaces [4]. They concluded that the reason was a change in creation and plowing of wear particles on the surface. This trapping effect should be active, even if melt bulges were removed but channels still present. The fact that laser textures did not reduce wear without melt bulges shows that this does not seem to be the main effect on the tribological behavior either.

Hu et al. [6] found a similarly discrete tribological behavior for laser surface textured Ti6Al4V in pin on disc experiments, depending on dimple diameter, oil viscosity, normal load and sliding speed. While acknowledging the effects of secondary lubrication and micro hydrodynamic lift, they also mentioned the reduction in contact area, leading to a decrease in adhesion and therefore friction.

In short, many researchers have investigated the tribology of textured surfaces and some mechanisms based on topography have become widely accepted. 

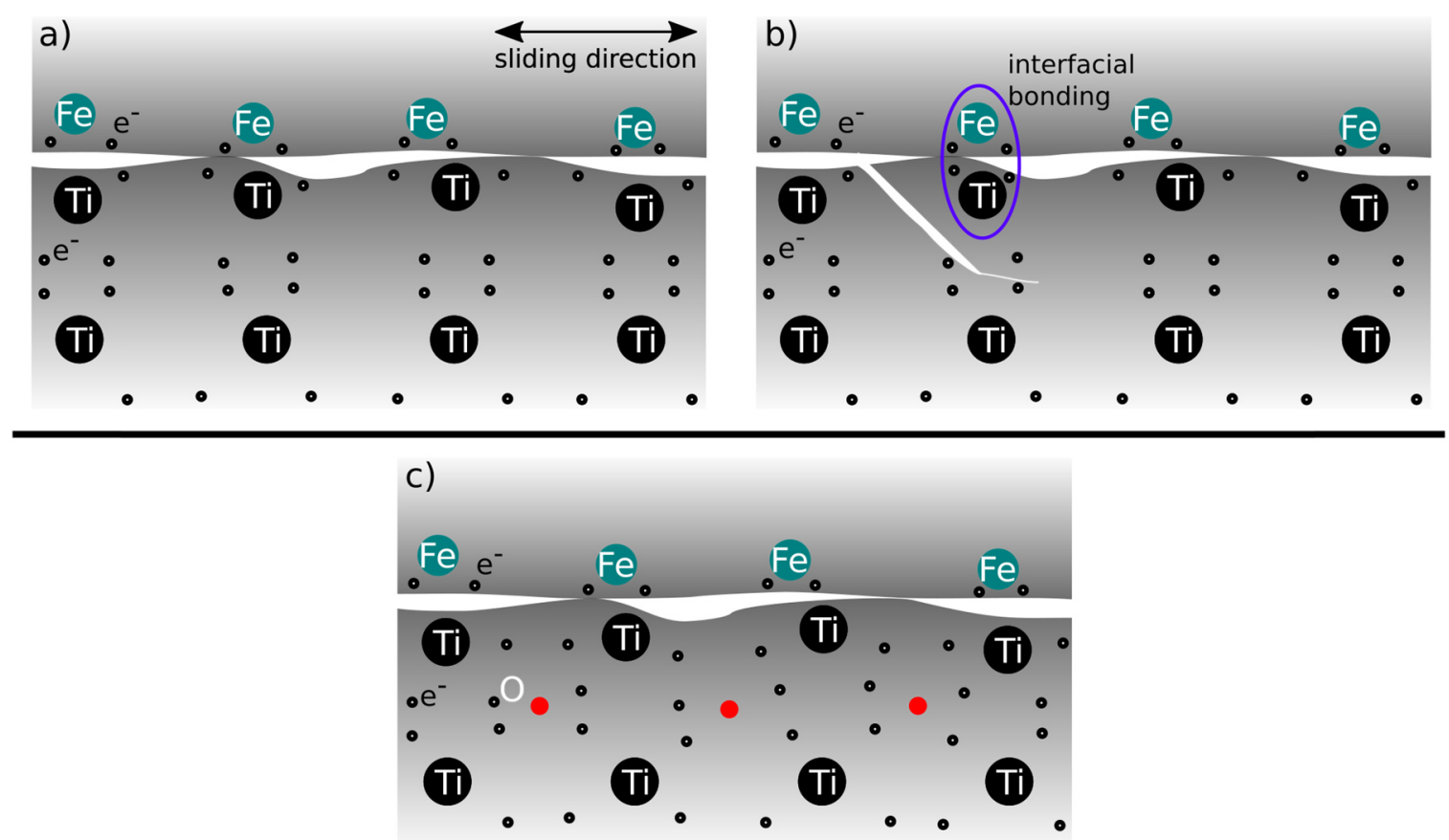

Fig. 10. Schematic representation of the effect of interstitial oxygen in a titanium lattice on the tribological response. During tribological contact, the unfavorable electronic structure of titanium leads to interfacial bonding with the steel counter body (a) and subsequently to formation of adhesive wear (b). Interstitial oxygen inhibits interfacial bonding by changing the electron distribution in the lattice and saturating possible bonds (c). Titanium surface oxide is assumed to be removed in tribological contacts [34]; lubricating medium was omitted for simplicity.

However, in addition to the inactive mechanisms discussed above, two experiments reveal that topography is not the major effect on the tribological response in the experiments shown here. The samples of $10 \%$ PD textured in argon and air have comparable topography with astextured melt bulges but yielded completely different tribological results. The same is true for $200 \%$ PD (ground) and the reference: similar, smooth topography but opposing tribological results.

\subsection{Influence of melt bulge hardness}

For the experiments where atmosphere during laser texturing was varied, wear resistance correlates with a high content of oxygen/nitrogen and a high hardness of the melt bulges. Martensitic microstructure in titanium alloys was reported to only exhibit mild strengthening effect $[29,30]$, and could not be measured in the melt bulges lasered in argon atmosphere (Table 3 ). It could still influence the wear behavior because martensite can inhibit the formation of localized shear bands and therefore crack propagation [31]. The increased hardness can be related to contents of oxygen and nitrogen, however. These interstitial elements preferably occupy octahedral interstitial sites in titanium, expanding the hexagonal lattice by increasing the $\mathrm{c} / \mathrm{a}$ ratio and therefore restricting the number of dislocation slip systems [32]. Besides an increased hardness [19], higher interstitial contents can lead to an increase in work hardening of pure titanium [33]. Both work hardening and hardness are deemed tribologically beneficial because they limit plastic deformation and therefore the junction growth of Ti6Al4V in tribological contact [2,34]. Researchers have investigated the tribological performance of nanocrystalline titanium prepared by different techniques, exhibiting higher hardness compared to coarsegrained titanium. Results range from considerable improvement [35] to no improvement of wear resistance or coefficient of friction [36] while others even found a detrimental effect of the processing [37]. However, all researchers reported a transition in tribological properties which is continuous to a certain degree and no discrete behavior as described here. Yet, the altered microstructure and plastic behavior could influence subsurface deformation and crack propagation in a way that wear behavior is critically affected. The limitation of plastic deformation is therefore thought to play a crucial role in the results shown here.

\subsection{Influence of oxygen and nitrogen content}

Considering the distinct decrease in wear by more than two orders of magnitude, it is plausible that there are additional influences on the tribology of titanium, besides the mechanisms of plastic deformation and work hardening.

Researchers already have applied several techniques like ion implantation [38], nitriding and carburizing [39] and especially thermal oxidation [2,3,40-43], in order to introduce interstitial elements like oxygen or nitrogen into the titanium lattice. Again, the tribological enhancing mechanism repeatedly mentioned was the restriction of plastic deformation. A decrease in chemical reactivity has also been proposed for interstitial-rich titanium [38] and can similarly be concluded from improved tribo-corrosion behavior [44], but no comprehensive explanation for this change in reactivity has been given yet.

Among other factors, the electronic structure of materials is considered to have an influence on their degree of adhesion and adhesive wear $[45,46]$. Russian scientists pointed out that the tribological properties of titanium may be connected to its high amount of nonlocalized valence electrons $[47,48]$. Also Buckley correlated the electronic structure of several pure metals to their coefficient of friction in contact with various ceramics [49,50] and with themselves [51].

Sargent and Conrad [52] claimed that lattice expansion due to interstitial oxygen cannot solely account for the pronounced solid solution strengthening found in titanium and concluded that interstitial oxygen is therefore chemically bound to the titanium lattice atoms. They based their argumentation, besides other observations, on the unusually high activation energy for diffusion of oxygen in titanium. The aspect of "covalent-like" chemical bonding of oxygen atoms in a titanium matrix was also mentioned in [53] and later confirmed by simulations [54-56]. Interstitial oxygen was accordingly shown to increase the charge density between titanium atoms around the interstitial sites $[57,58]$. 
Combining the two arguments on the electronic structure of titanium and interstitials, we propose the following tribological mechanism (Fig. 10). The solid solution of oxygen (and nitrogen) influences the electron distribution in the titanium lattice in a way that its electrons are more localized and bound around interstitial sites inside the lattice. The electronic bonds of titanium are therefore at least partially saturated by surrounding oxygen and nitrogen interstitials. As a result, the titanium surface is chemically less active and exhibits reduced interaction of valence electrons with the tribological counter body. The formation of strong adhesive bonds is hindered, what can ultimately be observed as the absence of adhesive wear in the tribological experiments.

Also note that in Fig. 1, the final coefficient of friction is comparable for all of the experiments. The fact that some experiments show a pronounced running-in behavior is believed to be based on the influence of oxygen as well. The running-in period would then be the time until a sufficient amount of oxygen is gathered in the wear track. This could not be shown experimentally due to limitations in control of ambient atmosphere at the tribometer. However, it is consistent with the observation, that with initially high oxygen content in the subsurface material (melt bulges), a running-in process is rendered unnecessary.

While the tribological enhancement seems based on the solid solution of oxygen and nitrogen in the melt bulges, packing densities of $2.5 \%$ and below still yielded a poor wear resistance, comparable to that of the non-textured reference. This can be explained by the limited mechanical strength and, on a microscopic scale, delicate nature of the melt bulges. In these cases, the mechanical strength was too low in order to bear the tribological load.

Apart from the enhancing mechanisms discussed, another possibility is the better bonding of lubricant molecules to the surface of the laser surface textured Ti6Al4V, which is subject of ongoing research.

\section{Conclusion}

Laser surface texturing was used to create linear channel textures in order to improve the poor tribological properties of Ti6Al4V. The research focused on the adjacent melt bulges created due to the use of a nanosecond-pulsed laser source. By a variation in channel packing density, finishing procedure and atmosphere during lasering, active enhancing mechanisms were elucidated.

1. Non-textured reference samples showed severe adhesive wear and high friction during the running-in period. In contrast, laser surface textured samples yielded a constant, low friction and wear was significantly reduced by up to a factor of 160 compared to reference samples.

2. Laser textures were only effective for channel packing densities of $5 \%$ and above, provided they were lasered in air and melt bulges were not removed before the experiment.

3. The topography of textures had no major effect on the tribological properties since samples with comparable topography yielded opposing tribological results.

4. Further investigation of the melt bulges by STEM and EDX revealed a purely martensitic $\alpha^{\prime}$-microstructure and increased contents in oxygen and nitrogen.

5. Solid solution of these interstitial elements seems to be the reason for enhancing the tribological properties of Ti6Al4V. The critical limitation of plastic deformation and a saturation of electronic bonds of titanium atoms are thought to decrease the adhesive tendency and therefore prevent adhesive wear.

While we showed results of model experiments on textured surfaces which were flat in topography, this method seems easily applicable on other, curved surfaces which would occur in many tribological components such as bushings, bearings and gears.

\section{Acknowledgements}

The authors would like to thank the German BMWi for funding this work within the scope of the project FAWIBO (20Y1505C), headed by Liebherr-Aerospace.

\section{References}

[1] K.G. Budinski, Tribological properties of titanium alloys, Wear 151 (2) (1991) 203-217, https://doi.org/10.1016/0043-1648(91)90249-T.

[2] H. Dong, T. Bell, Enhanced wear resistance of titanium surfaces by a new thermal oxidation treatment, Wear 238 (2) (2000) 131-137, https://doi.org/10.1016/ S0043-1648(99)00359-2.

[3] D.G. Bansal, O.L. Eryilmaz, P.J. Blau, Surface engineering to improve the durability and lubricity of Ti-6Al-4V alloy, Wear 271 (9-10) (2011) 2006-2015, https://doi. org/10.1016/j.wear.2010.11.021.

[4] H. Tian, N. Saka, N.P. Suh, Boundary lubrication studies on undulated titanium surfaces, Tribol. Trans. 32 (3) (1989) 289-296, https://doi.org/10.1080/ 10402008908981891.

[5] E. Segebade, D. Kümmel, F. Zanger, J. Schneider, V. Schulze, Surface texturing of TiAl6V4 using cutting tools in reverse, Procedia Manuf. 18 (2018) 97-103, https:// doi.org/10.1016/j.promfg.2018.11.013.

[6] T. Hu, L. Hu, Q. Ding, The effect of laser surface texturing on the tribological behavior of Ti-6Al-4V, Proc. Inst. Mech. Eng. Part J: J. Eng. Tribology 226 (10) (2012) 854-863, https://doi.org/10.1177/1350650112450801.

[7] D. He, S. Zheng, J. Pu, G. Zhang, L. Hu, Improving tribological properties of titanium alloys by combining laser surface texturing and diamond-like carbon film, Tribol. Int. 82 (2015) 20-27, https://doi.org/10.1016/j.triboint.2014.09.017.

[8] M.R. Ripoll, R. Simič, J. Brenner, B. Podgornik, Friction and lifetime of laser surface-textured and MoS2-coated Ti6Al4V under dry reciprocating sliding, Tribol. Lett. 51 (2) (2013) 261-271, https://doi.org/10.1007/s11249-013-0170-6.

[9] W. Pfleging, R. Kumari, H. Besser, T. Scharnweber, J.D. Majumdar, Laser surface textured titanium alloy (Ti-6Al-4V): Part 1 - surface characterization, Appl. Surf. Sci. 355 (2015) 104-111, https://doi.org/10.1016/j.apsusc.2015.06.175.

[10] A. Cunha, A.P. Serro, V. Oliveira, A. Almeida, R. Vilar, M.-C. Durrieu, Wetting behaviour of femtosecond laser textured Ti-6Al-4V surfaces, Appl. Surf. Sci. 265 (2013) 688-696, https://doi.org/10.1016/j.apsusc.2012.11.085.

[11] A. Kovalchenko, O. Ajayi, A. Erdemir, G. Fenske, I. Etsion, The effect of laser surface texturing on transitions in lubrication regimes during unidirectional sliding contact, Tribol. Int. 38 (3) (2005) 219-225, https://doi.org/10.1016/j.triboint.2004.08. 004.

[12] D. Braun, C. Greiner, J. Schneider, P. Gumbsch, Efficiency of laser surface texturing in the reduction of friction under mixed lubrication, Tribol. Int. 77 (2014) 142-147, https://doi.org/10.1016/j.triboint.2014.04.012.

[13] K.C. Phillips, H.H. Gandhi, E. Mazur, S.K. Sundaram, Ultrafast laser processing of materials: a review, Adv. Opt. Photon. 7 (4) (2015) 684, https://doi.org/10.1364/ AOP.7.000684.

[14] S.P. Mishra, A.A. Polycarpou, Tribological studies of unpolished laser surface textures under starved lubrication conditions for use in air-conditioning and refrigeration compressors, Tribol. Int. 44 (12) (2011) 1890-1901, https://doi.org/10. 1016/j.triboint.2011.08.005.

[15] A. Amanov, R. Tsuboi, H. Oe, S. Sasaki, The influence of bulges produced by laser surface texturing on the sliding friction and wear behavior, Tribol. Int. 60 (2013) 216-223, https://doi.org/10.1016/j.triboint.2012.10.018.

[16] C. Greiner, M. Schäfer, Bio-inspired scale-like surface textures and their tribological properties, Bioinspir. Biomim. 10 (4) (2015) 44001, https://doi.org/10.1088/17483190/10/4/044001

[17] L. Rapoport, A. Moshkovich, V. Perfilyev, I. Lapsker, G. Halperin, Y. Itovich, I. Etsion, Friction and wear of MoS2 films on laser textured steel surfaces, Surf. Coat. Technol. 202 (14) (2008) 3332-3340, https://doi.org/10.1016/j.surfcoat. 2007.12.009.

[18] M. Varenberg, G. Halperin, I. Etsion, Different aspects of the role of wear debris in fretting wear, Wear 252 (11-12) (2002) 902-910, https://doi.org/10.1016/S00431648(02)00044-3.

[19] W.L. Finlay, J.A. Snyder, Effects of three interstitial solutes (nitrogen, oxygen, and carbon) on the mechanical properties of high-purity, alpha titanium, JOM 2 (2) (1950) 277-286, https://doi.org/10.1007/BF03399001.

[20] J. Qu, P.J. Blau, T.R. Watkins, O.B. Cavin, N.S. Kulkarni, Friction and wear of titanium alloys sliding against metal, polymer, and ceramic counterfaces, Wear 258 (9) (2005) 1348-1356, https://doi.org/10.1016/j.wear.2004.09.062.

[21] G. Lütjering, J.C. Williams, Titanium, 2nd ed., Springer Berlin Heidelberg, Berlin, Heidelberg, 2007

[22] T. Ahmed, H.J. Rack, Phase transformations during cooling in $\alpha+\beta$ titanium alloys, Mater. Sci. Eng.: A 243 (1-2) (1998) 206-211, https://doi.org/10.1016/S09215093(97)00802-2.

[23] S.K. Sundaram, E. Mazur, Inducing and probing non-thermal transitions in semiconductors using femtosecond laser pulses, Nat. Mater. 1 (4) (2002) 217, https:// doi.org/10.1038/nmat767.

[24] M. Yan, W. Xu, M.S. Dargusch, H.P. Tang, M. Brandt, M. Qian, Review of effect of oxygen on room temperature ductility of titanium and titanium alloys, Powder Metall. 57 (4) (2014) 251-257, https://doi.org/10.1179/1743290114Y.0000000108.

[25] H. Okamoto, O-Ti (Oxygen-titanium), J. Phase Equilib. Diffus. 32 (5) (2011) 473-474, https://doi.org/10.1007/s11669-011-9935-5. 
[26] H. Okamoto, N-Ti (Nitrogen-titanium), J. Phase Equilib. Diffus. 34 (2) (2013) 151-152, https://doi.org/10.1007/s11669-012-0153-6.

[27] A. Ramesh, W. Akram, S.P. Mishra, A.H. Cannon, A.A. Polycarpou, W.P. King, Friction characteristics of microtextured surfaces under mixed and hydrodynamic lubrication, Tribol. Int. 57 (2013) 170-176, https://doi.org/10.1016/j.triboint. 2012.07.020

[28] X. Lu, M.M. Khonsari, An experimental investigation of dimple effect on the stribeck curve of journal bearings, Tribol. Lett. 27 (2) (2007) 169, https://doi.org/10.1007/ s11249-007-9217-x.

[29] C. Leyens, M. Peters, Titanium and Titanium Alloys: Fundamentals and Applications, Wiley-VCH, Weinheim, Chichester, 2003.

[30] R. Dąbrowski, The kinetics of phase transformations during continuous cooling of the Ti6Al4V alloy from the single-phase $\beta$ range, Arch. Metall. Mater. 56 (3) (2011) 703-707, https://doi.org/10.2478/v10172-011-0077-x.

[31] S.V. Telrandhe, B. Jayabalan, C.P. Paul, S.K. Mishra, Microstructural development due to laser treatment and its effect on machinability of Ti6Al4V alloy, Metall. Mater. Trans. A 49 (8) (2018) 3450-3467, https://doi.org/10.1007/s11661-018 4728-7.

[32] J.-M. Oh, B.-G. Lee, S.-W. Cho, S.-W. Lee, G.-S. Choi, J.-W. Lim, Oxygen effects on the mechanical properties and lattice strain of Ti and Ti-6Al-4V, Met. Mater. Int. 17 (5) (2011) 733-736.

[33] D.-s. Kang, K.-j. Lee, E.-p. Kwon, T. Tsuchiyama, S. Takaki, Variation of work hardening rate by oxygen contents in pure titanium alloy, Mater. Sci. Eng.: A 632 (2015) 120-126, https://doi.org/10.1016/j.msea.2015.02.074.

[34] A. Molinari, G. Straffelini, B. Tesi, T. Bacci, Dry sliding wear mechanisms of the Ti6Al4V alloy, Wear 208 (1-2) (1997) 105-112, https://doi.org/10.1016/S0043 1648(96)07454-6.

[35] S. Alikhani Chamgordani, R. Miresmaeili, M. Aliofkhazraei, Improvement in tribological behavior of commercial pure titanium (CP-Ti) by surface mechanical attrition treatment (SMAT), Tribol. Int. 119 (2018) 744-752, https://doi.org/10. 1016/j.triboint.2017.11.044.

[36] J.E. Mogonye, T.W. Scharf, Tribological properties and mechanisms of self-mated ultrafine-grained titanium, Wear 376-377 (2017) 931-939, https://doi.org/10. 1016/j.wear.2016.10.016.

[37] H. Garbacz, M. Grądzka-Dahlke, K.J. Kurzydłowski, The tribological properties of nano-titanium obtained by hydrostatic extrusion, Wear 263 (1-6) (2007) 572-578, https://doi.org/10.1016/j.wear.2006.11.047.

[38] J.I. Oñate, F. Alonso, A. García, Improvement of tribological properties by ion implantation, Thin Solid Films 317 (1-2) (1998) 471-476, https://doi.org/10. 1016/S0040-6090(97)00564-6.

[39] A. Zhecheva, W. Sha, S. Malinov, A. Long, Enhancing the microstructure and properties of titanium alloys through nitriding and other surface engineering methods, Surf. Coat. Technol. 200 (7) (2005) 2192-2207, https://doi.org/10.1016/ j.surfcoat.2004.07.115

[40] L. Cao, J. Liu, Y. Wan, S. Yang, J. Gao, J. Pu, Low-friction carbon-based tribofilm from poly-alpha-olefin oil on thermally oxidized Ti6Al4V, Surf. Coat. Technol. 337 (2018) 471-477, https://doi.org/10.1016/j.surfcoat.2018.01.057.

[41] F. Borgioli, E. Galvanetto, F. Iozzelli, G. Pradelli, Improvement of wear resistance of Ti-6Al-4V alloy by means of thermal oxidation, Mater. Lett. 59 (17) (2005)
2159-2162, https://doi.org/10.1016/j.matlet.2005.02.054.

[42] Q. Sun, T. Hu, H. Fan, Y. Zhang, L. Hu, Thermal oxidation behavior and tribological properties of textured TC4 surface: influence of thermal oxidation temperature and time, Tribol. Int. 94 (2016) 479-489, https://doi.org/10.1016/j.triboint.2015.10. 013.

[43] R. Bailey, Tribocorrosion response of surface-modified Ti in a $0.9 \% \mathrm{NaCl}$ solution, Lubricants 6 (4) (2018) 86, https://doi.org/10.3390/lubricants6040086.

[44] R.A. Buchanan, E.D. Rigney, J.M. Williams, Ion implantation of surgical Ti-6Al-4V for improved resistance to wear-accelerated corrosion, J. Biomed. Mater. Res. 21 (3) (1987) 355-366, https://doi.org/10.1002/jbm.820210308.

[45] H. Czichos, The mechanism of the metallic adhesion bond, J. Phys. D: Appl. Phys. 5 (10) (1972) 1890-1897, https://doi.org/10.1088/0022-3727/5/10/321.

[46] B.V. Derjaguin, V.P. Smilga, Electronic theory of adhesion, J. Appl. Phys. 38 (12) (1967) 4609, https://doi.org/10.1063/1.1709192.

[47] G.V. Samsonov, A.Y. Artamonov, I.F. Idzon, Interaction between the metal and the abrasive in Coulomb friction, Soviet, Powder Metall. Metal. Ceram. 6 (11) (1967) 913-919, https://doi.org/10.1007/BF00773855.

[48] I.G. Nosovskii, A.A. Zaporozhets, Investigation of the friction and wear of certain metals in liquid nitrogen, Sov. Mater. Sci. a Transl. Fiz.-khimicheskaya mekhanika Mater./Acad. Sci. Ukr. SSR 4 (5) (1971) 416-419, https://doi.org/10.1007/ BF00721444.

[49] D.H. Buckley, K. Miyoshi, Friction and wear of ceramics, Wear 100 (1-3) (1984) 333-353, https://doi.org/10.1016/0043-1648(84)90020-6.

[50] K. Miyoshi, D.H. Buckley, Friction and wear of single-crystal manganese-zinc ferrite, Wear 66 (2) (1981) 157-173, https://doi.org/10.1016/0043-1648(81) 90111-3.

[51] D.H. Buckley, The metal-to-metal interface and its effect on adhesion and friction, Plenary Invit. Lect. (1977) 37-54, https://doi.org/10.1016/B978-0-12-404501-9. 50012-2.

[52] G.A. Sargent, H. Conrad, On the strengthening of titanium by oxygen, Scr. Metall. 6 (11) (1972) 1099-1101, https://doi.org/10.1016/0036-9748(72)90196-2.

[53] H. Nakajima, M. Koiwa, Diffusion in titanium, ISIJ Int. 31 (8) (1991) 757-766, https://doi.org/10.2355/isijinternational.31.757.

[54] P. Kwasniak, M. Muzyk, H. Garbacz, K.J. Kurzydlowski, Influence of oxygen content on the mechanical properties of hexagonal Ti-first principles calculations, Mater. Sci. Eng.: A 590 (2014) 74-79, https://doi.org/10.1016/j.msea.2013.10.004.

[55] Q. Yu, L. Qi, T. Tsuru, R. Traylor, D. Rugg, J.W. Morris, M. Asta, D.C. Chrzan, A.M. Minor, Origin of dramatic oxygen solute strengthening effect in titanium, Science 347 (6222) (2015) 635-639, https://doi.org/10.1126/science.1260485.

[56] L. Scotti, A. Mottura, Interstitial diffusion of O, N, and C in $\alpha$-Ti from first-principles: analytical model and kinetic Monte Carlo simulations, J. Chem. Phys. 144 (8) (2016) 84701, https://doi.org/10.1063/1.4942030.

[57] Y. Song, Z.X. Guo, R. Yang, Influence of interstitial elements on the bulk modulus and theoretical strength of a-titanium: a first-principles study, Philos. Mag. A 82 (7) (2002) 1345-1359, https://doi.org/10.1080/01418610208235676.

[58] M.A. Bhatia, X. Zhang, M. Azarnoush, G. Lu, K.N. Solanki, Effects of oxygen on prismatic faults in $\alpha$-Ti: a combined quantum mechanics/molecular mechanics study, Scr. Mater. 98 (2015) 32-35, https://doi.org/10.1016/j.scriptamat.2014.11. 008 . 
Karlsruher Institut für Technologie

\section{Repository KITopen}

Dies ist ein Postprint/begutachtetes Manuskript.

Empfohlene Zitierung:

Kümmel, D.; Hamann-Schroer, M.; Hetzner, H.; Schneider, J.

Tribological behavior of nanosecond-laser surface textured Ti6Al4V.

2019. Wear.

doi:10.5445/IR/1000091065

Zitierung der Originalveröffentlichung:

Kümmel, D.; Hamann-Schroer, M.; Hetzner, H.; Schneider, J.

Tribological behavior of nanosecond-laser surface textured Ti6Al4V. 2019. Wear, 422-423, 261-268.

doi:10.1016/j.wear.2019.01.079 